IRA-International Journal of Applied Sciences ISSN 2455-4499; Vol.06, Issue 02 (2017)

Institute of Research Advances

Pg. no. 34-40

https://research-advances.org/index.php/IRAJAS

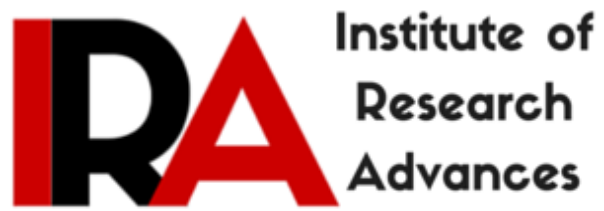

\title{
Shelf Life of Trichoderma Harzianum an Antagonist in Different Oil Based Formulations
}

\author{
Ahamedemujtaba, V. ${ }^{1}$ and Shripad Kulkarni ${ }^{2}$ \\ ${ }^{1,2}$ Department of Plant Pathology College of Agriculture, \\ University of Agricultural Sciences, Dharwad - 580 005, Karnataka, India.
}

Type of Review: Peer Reviewed.

DOI: http://dx.doi.org/10.21013/jas.v6.n2.p2

\section{How to cite this paper:}

V., A., \& Kulkarni, S. (2017). Shelf Life of Trichoderma Harzianum an Antagonist in Different Oil Based Formulations. IRA-International Journal of Applied Sciences (ISSN 2455-4499), 6(2), 34-40. doi:http://dx.doi.org/10.21013/jas.v6.n2.p2

(C) Institute of Research Advances

\section{(cc) EY-NC}

This work is licensed under a Creative Commons Attribution-Non Commercial 4.0 International License subject to proper citation to the publication source of the work.

Disclaimer: The scholarly papers as reviewed and published by the Institute of Research Advances (IRA) are the views and opinions of their respective authors and are not the views or opinions of the IRA. The IRA disclaims of any harm or loss caused due to the published content to any party. 


\section{ABSTRACT}

Trichoderma is a promising candidate for the biological control of plant pathogenic fungi. While planning the application of antagonistic Trichoderma strains for the purposes of biological control, it is very important to consider the environmental parameters affecting the bio-control agents in the soil. A series of abiotic and biotic environmental parameters has an influence on the bio-control efficacy of Trichoderma. The major bottleneck of bio-pesticides is the shelf life and inconsistent performance. In order to overcome this problem, the present study the liquid formulation was used to increase the shelf life of Trichoderma. Oils like Canole oil, paraffin oil, soya bean oil, Neem oil and Glycerol and their combination of paraffin oil and glycerol, paraffin oil and Soya bean oil, Canola oil and Glycerol, and Paraffin oil and Neem oil were used, among which Canola oil + Glycerol based formulation and Paraffin oil based formulation with $3.00 \times 104 \mathrm{Cfu} / \mathrm{ml}$ and $2.00 \times 104 \mathrm{Cfu} / \mathrm{ml}$ viable conidia showed extended shelf life of twelve months of storage.

\section{Introduction}

Some of the bio-pesticides and other beneficial organism based formulations are very effective in laboratory conditions but fail in field occasionally. Reasons for this are poor stability of the product during storage prior to application, too little active material actually reaching the field target, death of the antagonistic used due to desiccation, contamination of formulation and rapid degradation of active material on the target. Formulation type plays an important role in helping to solve these problems and making a formulation very effective even in the fields. Thus, water/oil emulsions appear to be a promising, yet under-utilized, method for storing and delivering microorganisms to aqueous environments. One of the advantages of water/oil emulsions over other methods of formulation is that the oil traps water around the organism and slows water evaporation once applied. This is particularly beneficial for organisms that are sensitive to desiccation (Jean et al., 2006).

Foliar diseases besides reducing the yield, also have an adverse influence on seed quality and grade characteristics, deteriorate the quality of plant biomass and thus render the fodder unsuitable as animal feed. Further, control of these diseases through the application of plant protection measures will not only increase the cost of cultivation but also lead to environmental and health hazards. The seeds harvested from unsprayed plots will have significantly better quality than those treated with Chlorothalonil, a fungicide used to control rust and LLS in groundnuts (Hammonds et al., 1976). That's why, though chemical control is possible, development and use of oil-based formulations of bio-control agent can be considered to be the best strategy for reducing crop losses due to these diseases, which would be effective in decreasing cultivation costs, environmental safety in addition to management of the diseases. In this context, the present investigation was undertaken formulating different oil based formulations of Trichoderma spps.

\section{Material and Methods}

Present investigation was carried out during the period 2009-2010 at University of Agricultural Sciences, Dharwad. Laboratory experiments were carried out in Institute of Organic Farming, College of Agriculture, University of Agricultural Sciences, Dharwad, Karnataka.

Soil samples from different locations were collected. Procedures of cleaning glassware's and sterilization were done as explained earlier. The procedures given by Ramakrishnan (1989) were used to isolate microorganism from the collected soil sample. The techniques of serial dilution and purification were done as suggested by Sankaram (1961) for identification at Institute of Organic Farming (I.O.F), University of Agricultural Sciences, Dharwad. 
Trichoderma Selective Medium (TSM) (Askew and Laing, 1993)

The basal medium used consisted of the following components:

$\begin{array}{lc}\mathrm{MgSO}_{4}\left(7 \mathrm{H}_{2} \mathrm{O}\right) & 0.2 \mathrm{~g} \\ \mathrm{~K}_{2} \mathrm{HPO}_{4} & 0.9 \mathrm{~g} \\ \mathrm{KCL} & 0.15 \mathrm{~g} \\ \mathrm{NH}_{4} \mathrm{NO}_{3} & 1.0 \mathrm{~g} \\ \text { Glucose anhydrous } & 3.0 \mathrm{~g} \\ \text { Rose Bengal } & 0.15 \mathrm{~g} \\ \text { Chloramphenicol } & 0.25 \mathrm{~g} \\ \text { Agar-agar } & 20.0 \mathrm{~g}\end{array}$

The constituents were added to $950 \mathrm{ml}$ of distilled water, made up to $1000 \mathrm{ml}$ and autoclaved at $121^{\circ} \mathrm{c}$ for $15 \mathrm{~min}$.

Mass multiplication on solid media (Tuite, 1969)

1. Potato Dextrose Agar

Potato Dextrose powder $\quad 20.00 \mathrm{~g}$

Agar-agar $\quad 20.00 \mathrm{~g}$

Distilled water $\quad 1000 \mathrm{ml}$

$\mathrm{pH} \quad 7.0$

Twenty gram Potato Dextrose powder and Agar-agar were dissolved in $800 \mathrm{ml}$ of distilled water. The volume was made up to $1000 \mathrm{ml}$ with distilled water and medium was sterilized at $1.1 \mathrm{~kg}$ per $\mathrm{cm}^{2}$ pressure for $15 \mathrm{~min}$.

\section{Preparation of oil based formulations}

The strain of Trichoderma harzianum originally isolated from soils of organic farming plot (D block) was mass multiplied on solid media (PDB). Isolate having characters such as very fast growth, virulent nature and adaptability in Dharwad zone was used for further studies.

The aerial conidia were grown on Potato Dextrose Agar Medium (PDA) in a Petri dish of 8 inch diameter at $25 \pm 0.5^{\circ} \mathrm{C}$. After 10 days, conidia were harvested using a spatula and then suspended in previously autoclaved different oils and combinations along with $2 \%$ dextrose. These formulations were further used for shelf life studies and field trials.

\section{Oil-based formulations and their compositions}

\begin{tabular}{|c|l|}
\hline Formulation & \multicolumn{1}{|c|}{ Composition } \\
\hline F-1 & Canola oil \\
\hline F-2 & Paraffin oil \\
\hline F-3 & Soybean oil \\
\hline
\end{tabular}




\begin{tabular}{|l|l|}
\hline F-4 & Glycerol \\
\hline F-5 & Neem oil \\
\hline F-6 & Paraffin oil + Glycerol $(1: 1)$ \\
\hline F-7 & Paraffin oil + Soybean oil $(1: 1)$ \\
\hline F-8 & Canola oil + Glycerol $(1: 1)$ \\
\hline F-9 & Paraffin oil + Neem oil $(1: 1)$ \\
\hline
\end{tabular}

\section{Shelf Life Studies}

The studies on shelf life of different 9 oil based formulations, one talc based formulation and one private liquid formulation were conducted starting from first day of formulations with a regular interval of 30 days till twelve months.

One $\mathrm{ml}$ aliquot from each stored conidial suspension was pipetted and serially diluted in $9 \mathrm{ml}$ distilled water blanks till $10^{6}$ dilution. All resultant diluted conidial formulations were then mixed using a whirl mixer for $3 \mathrm{~min}$. to homogenize the suspensions. Finally, a new aliquot of $0.1 \mathrm{ml}$ was pipetted from each treatment and thinly spread over the haemocytometer and covered with cover slip. Then, observed under compound microscope for viable spores and mycilial bits (Sathiyaseelan et al., 2009). Observations on the initial colony forming units (cfu) and colony forming units (cfu) after every month were recorded.

$\mathrm{cfu}=\frac{\text { No. of spores / mycelial bits observed }}{\text { No. of cells observed }} \times 400 \times 0.1 \times 1000 \times$ dilution factor

\section{Results and Discussion}

The results on the shelf life of Trichoderma harzianum expressed in terms of colony forming units and are presented in Table 1.

The Initial Colony forming unit CFU was between $\left(42-48 \times 10^{6} \mathrm{cfu} / \mathrm{ml}\right)$. The results indicated that after one month of incubation the maximum population was recorded in $\mathrm{T}_{10}-($ Talc based powder formulation) with $\left(43.33 \times 10^{6} \mathrm{cfu} / \mathrm{ml}\right)$ followed by $43.00,42.00$ and $41.00 \times 10^{6}$ $\mathrm{cfu} / \mathrm{ml})$ in $\mathrm{T}_{8}-$ (Canola oil + Glycerol based formulation), $\mathrm{T}_{4}-$ (Glycerol based formulation), $\mathrm{T}_{7}-$ (Paraffin oil + Soybean oil based formulation), respectively. The minimum population $(27.67 \mathrm{x}$ $\left.10^{6} \mathrm{cfu} / \mathrm{ml}\right)$ was recorded in $\mathrm{T}_{9}-$ (Paraffin oil + Neem oil based formulation).

There was drastic decrease in population in Paraffin oil + neem oil formulation after ninety days with only $2 \times 10^{6}$ cfu per ml but it was found moderate in Paraffin oil and Neem oil based formulations with 32 and $26.33 \times 10^{6} \mathrm{cfu}$ per $\mathrm{ml}$. There was a decrease in the population when soybean oil was used alone or in combination with Paraffin oil $\left(15 \times 10^{6} \mathrm{cfu} / \mathrm{ml}\right)$ after 120 days. The decrease in population was also conspicuous in private liquid formulations after 150 days.

The decrease in the population was progressively slow in $\mathrm{T}_{10}$ - (Talc based powder formulation), $\mathrm{T}_{6}$ (Paraffin oil + Glycerol) and $\mathrm{T}_{4}$ (Glycerol based formulation). After six months of incubation, the maximum population $\left(23.67 \times 10^{6} \mathrm{cfu} / \mathrm{ml}\right)$ was recorded in $\mathrm{T}_{8}$ (Canola oil + Glycerol based formulation) followed by $\left(23.00 \mathrm{x} \quad 10^{6} \mathrm{cfu} / \mathrm{ml}\right) \mathrm{T}_{4}$ (Glycerol based formulation). The population was nil in case of Paraffin oil + Neem oil based formulation from four months of incubation. After one year of incubation period colony forming unit was significantly low in all the treatments. 
Highest shelf life of 12 months was found in Canola oil + glycerol based formulation $\left(3 \times 10^{6}\right.$ $\mathrm{cfu} / \mathrm{ml})$ followed by paraffin oil based formulation $\left(2 \times 10^{6} \mathrm{cfu} / \mathrm{ml}\right)$.

Many workers while working with various bioagents have proved that their shelf life has improved significantly when these organisms are mixed with different oils/liquids in place of solid based substrates.

Contrary to the Moore et al. (1995) proved that long term storability of Metarrhizium flavoviride in oils such as soya and groundnut or mineral oil retaining 47 to 68 per cent viability and was after 16 to 18 months of storage. Even they observed the extended viability until 160 weeks (37 months). They also used these representative formulations of the stored conidia to test their bioassay against Schistocerea gregaria (upto 30 months) in their experiment and found that they retained full virulence as good as freshly prepared formulation.

In the present investigation also, the oil based formulations viz., Canola oil + Glycerol based formulation $32.00 \times 10^{4} \mathrm{cfu} / \mathrm{ml}$ ) followed by glycerol based formulation $29.33 \times 10^{4} \mathrm{cfu} / \mathrm{ml}$ ) showed the maximum viability after six months (Table 1). However, there was drastic decline in shelf life with some of the formulations such as soybean oil alone or in combination with Paraffin oil and Paraffin oil + Neem oil. Canola oil + Glycerol based formulation $3.00 \times 10^{4} \mathrm{cfu} / \mathrm{ml}$ ) followed by paraffin oil based formulation $2.00 \times 10^{4} \mathrm{cfu} / \mathrm{ml}$ ) were found with viable conidia in the oil based formulation till twelve months of storage. Viability and competitiveness of fungal mycelium and spores in a liquid medium was determined in vitro and results indicated that the amendments with greatest effect were the addition of dextrose as a food base has extended its shelf life.

Mainly researchers confirmed that the formulations of microbial biomass developed as biological control products grown in different liquid media of differing composition shown extended shelf life (Kolombet et al., 2000; Sathiyaseelan et al., 2009 and Krishan and Greep, 2010).

\section{References}

1. Bateman, R. P., Carey, M., Moore, D. and Prior, C. 1993. The enhanced infectivity of Metarhizium flavoviride in oil formulations to desert locusts at low humidities. Ann. Appl. Biol., 122(1) : 145-152 .

2. Chavan, B. P. and Kadam, J. R., 2009a, Effect of combination of adjuvants on liquid formulations of Verticillium lecanii (Zimmermann) Viegas and their efficacy. J. Biol. Control., 23(1) : 73-77.

3. Chavan, B. P. and Kadam, J. R., 2009b, Potential of liquid formulations of Verticillium lecanii against spiralling white fly, Aleurodicus disperses Russell. J. Biol. Control., 23(2) : 151-154.

4. Erkilic, L., 1992. Studies on the use of oil based formulations of Verticillium-lecanii against green peach aphid. Myzus-persicae, p. 113.

5. Hammonds, J. M., Buckeman, P. A. and Lyle, J. A., 1976, Peanut fungicides : relationships between leaf spot control and quality. Peanut Sci. $3:$ 70-72.

6. Jean, S. V., Herbert, S, and Hong, Y. G. 2006, Design of formulations for improved biological control agent viability and sequestration during storage. Industrial Biotechnol., 3 : 213-219

7. Kolombet, L. V., Zhigletsova, S. K., Kosareva, N. I., Bystrova, E. V., Derbyshev, $\quad$ V. V., Krasnova , S. P. and Schisler, D., 2008, Development of an extended shelf-life, liquid formulation of the biofungicide Trichoderma asperellum. World J. Microbiol. Biotechnol., 24 :123-131.

8. Krishan, C. and Greep, S. 2010. Liquid based bio-fertilizers. J. Ecofriendly Agric., 5(1) : 1-7. 
9. Manjula, C., et al 2003 . Evaluation of different oil formulations of bio-agent, Beauveria bassiana against different life stages of Bemisia tabaci, the vector of tomato leaf curl virus. Plant Dis. Res., Ludhiana, 18(1) : 25-28 .

10. Moore, D., Bateman, R. P., Carey, M. and Prior, C. 1995 . Long-term storage of Metarhizium flavoviride conidia in oil formulations for the control of locusts and grasshoppers . Biocontrol Sci. Technol., 5(2) : 193-199.

11. Sathiyaseelan, K., Sivasakthivelan, P. and Lenin, G. 2009. Evaluation of antagonastic activity and shelf life study of Trichoderma viride. Botany Res. Int., $\quad 2(3):$ 195-197.

12. Verhaar, M. A., Hijwegen, T. and Zadoka, J. C. 1999 . Improvement of the efficacy of Verticillium lecaniii used in biocontrol of Sphaerotheca fuliginea by addition of oil formulations. Biocontrol. 44(1) : 73-87.

13. Yasuda, K., Toyosato, T. and Takaesu, K. 2000, Enhanced infectivity of oil formulations of Beauveria bassiana to Cylas formicarius (Fabricius) (Coleoptera : Curculionidae). Japanese J. Appl. Entomol. Zool., 44(4) : 241-243. 
Table 1: Shelf life of Trichoderma harzianum in different formulations

\begin{tabular}{|c|c|c|c|c|c|c|c|c|c|c|c|c|c|c|}
\hline \multirow{2}{*}{$\begin{array}{c}\text { Treat. } \\
\text { No. }\end{array}$} & \multirow{2}{*}{ Treatments } & \multicolumn{13}{|c|}{ Colony forming units (cfu) at different days $\left(10^{6}\right)$} \\
\hline & & Initial & 30 & 60 & 90 & 120 & 150 & 180 & 210 & 240 & 270 & 300 & 330 & 360 \\
\hline $\mathrm{T}_{1}$ & Canola oil & 48.23 & 39.33 & 35.33 & 31.00 & 27.00 & 24.67 & 22.00 & 19.00 & 15.33 & 12.67 & 8.00 & 5.00 & 1.67 \\
\hline $\mathrm{T}_{2}$ & Paraffin oil & 46.00 & 37.33 & 34.67 & 32.00 & 29.33 & 26.00 & 21.33 & 19.33 & 16.67 & 14.00 & 8.67 & 5.67 & 2.00 \\
\hline $\mathrm{T}_{3}$ & Soybean oil & 46.56 & 38.67 & 25.33 & 13.67 & 6.33 & 2.67 & 0.67 & 0.00 & 0.00 & 0.00 & 0.00 & 0.00 & 0.00 \\
\hline $\mathrm{T}_{4}$ & Glycerol & 48.35 & 42.00 & 37.67 & 33.00 & 29.33 & 26.33 & 23.00 & 20.00 & 16.33 & 11.67 & 5.33 & 1.00 & 0.00 \\
\hline $\mathrm{T}_{5}$ & Neem oil & 43.37 & 35.33 & 31.00 & 26.33 & 22.00 & 17.00 & 12.67 & 6.67 & 2.33 & 0.00 & 0.00 & 0.00 & 0.00 \\
\hline $\mathrm{T}_{6}$ & Paraffin oil + Glycerol (1:1) & 46.67 & 40.00 & 36.67 & 33.00 & 27.67 & 25.00 & 21.33 & 17.67 & 13.67 & 10.00 & 6.33 & 3.33 & 1.67 \\
\hline $\mathrm{T}_{7}$ & Paraffin oil + Soybean oil (1:1) & 47.52 & 41.00 & 30.67 & 21.67 & 15.67 & 9.33 & 4.67 & 2.00 & 0.00 & 0.00 & 0.00 & 0.00 & 0.00 \\
\hline $\mathrm{T}_{8}$ & Canola oil + Glycerol & 48.79 & 43.00 & 38.67 & 35.00 & 32.00 & 27.33 & 23.67 & 20.67 & 17.67 & 14.33 & 10.00 & 5.00 & 3.00 \\
\hline $\mathrm{T}_{9}$ & Paraffin oil + Neem oil & 40.46 & 27.67 & 9.67 & 2.00 & 0.00 & 0.00 & 0.00 & 0.00 & 0.00 & 0.00 & 0.00 & 0.00 & 0.00 \\
\hline $\mathrm{T}_{10}$ & Talc based & 48.88 & 43.33 & 35.00 & 31.33 & 23.67 & 17.33 & 12.00 & 7.33 & 3.33 & 0.67 & 0.00 & 0.00 & 0.00 \\
\hline \multirow[t]{6}{*}{$\mathrm{T}_{11}$} & Private Liquid formulation & 46.12 & 37.33 & 25.67 & 19.33 & 13.33 & 3.33 & 1.00 & 0.00 & 0.00 & 0.00 & 0.00 & 0.00 & 0.00 \\
\hline & Mean & & 424.99 & 340.35 & 278.33 & 226.33 & 178.99 & 142.34 & 112.67 & 85.33 & 63.34 & 38.33 & 20.00 & 8.34 \\
\hline & & SEm \pm & $\begin{array}{c}\text { CD } \\
(\mathbf{0 . 0 1})\end{array}$ & & & & & & & & & & & \\
\hline & CFU & 0.298 & 0.83 & & & & & & & & & & & \\
\hline & INT & 0.312 & 0.87 & & & & & & & & & & & \\
\hline & CFU $x$ INT & 1.034 & 2.88 & & & & & & & & & & & \\
\hline
\end{tabular}

** Numericals indicates CFU Count in a petriplate 